Teatro do Oprimido: síntese histórica do Arena ou narrativa de resistência do encontro de Augusto Boal com a pedagogia do teatro?

Theatre of the Oppressed: historical synthesis of Arena or resistance narrative of the meeting of Augusto Boal with

Theatrical Pedagogy?

\title{
Dodi Leal
}

Dodi Leal

Doutorando dp PPGPS do Instituto de Psicologia da USP

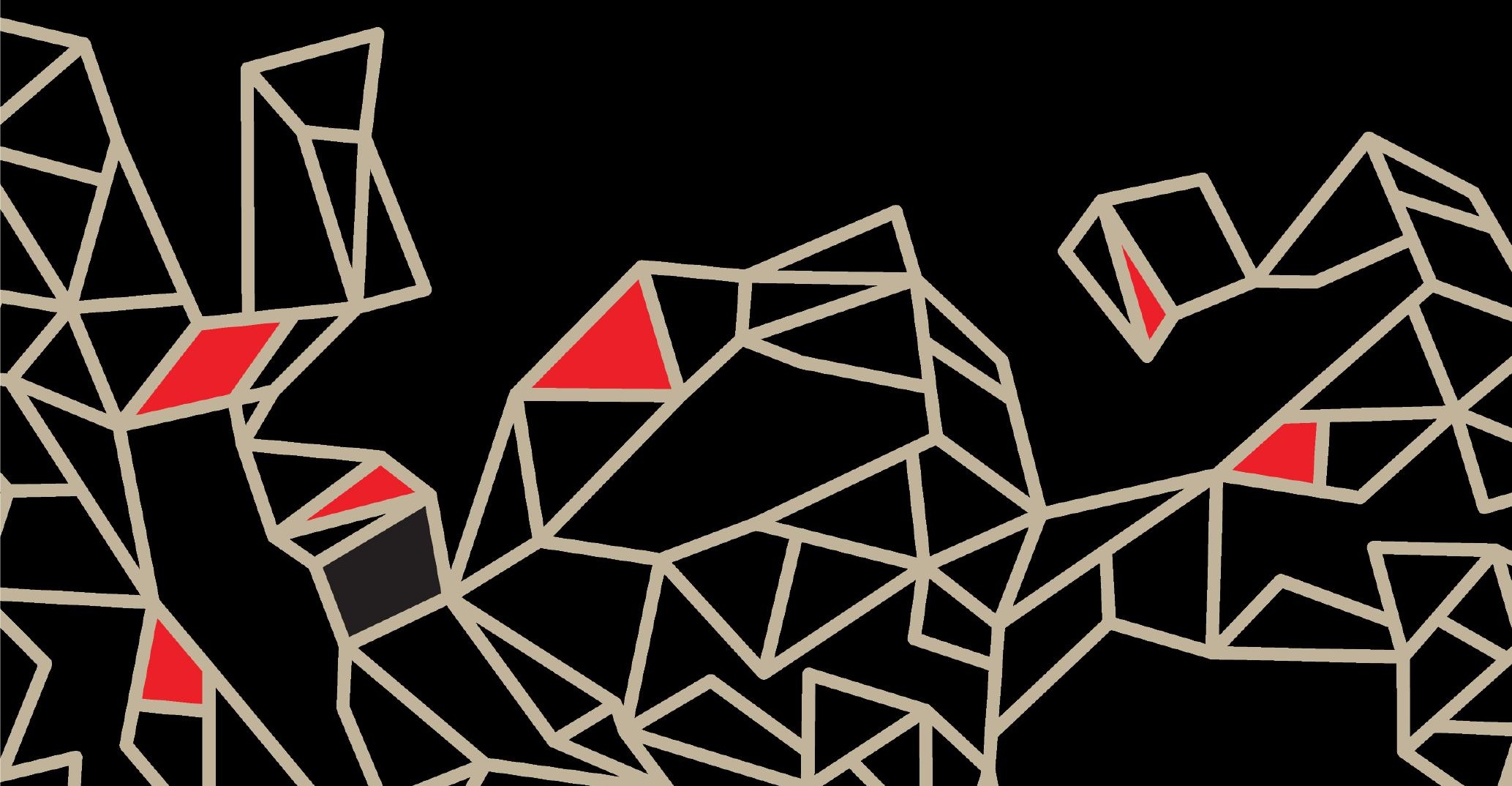




\section{Resumo}

Este artigo pretende analisar os principais fatores históricos que levaram Augusto Boal a novas propostas de recepção e encenação com o Teatro do Oprimido. Sob a ótica da crítica foucaultiana, o Teatro do Oprimido é discutido como um projeto contemporâneo que dá continuidade e, ao mesmo tempo, resiste à moderna pedagogia teatral de Stanislavski (dirigida à noção de sujeito e cuidado de si) forjando uma pedagogia teatral da biopolítica que incorpora em seu escopo dramatúrgico e improvisacional tecnologias avançadas de julgamento e decisão de problemas (opressões) populacionais.

Palavras-chave: Teatro do Oprimido, Pedagogia do teatro, Augusto Boal, Michel Foucault.

\section{Abstract}

This paper intends to analyze the main historical factors that led Augusto Boal to new proposals of reception and staging with the Theatre of the Oppressed. From the perspective of Foucault's critique, Theatre of the Oppressed is discussed as a contemporary project that simultaneously continues and resists to Stanislavski's modern theatrical pedagogy (addressed to the notion of subject and care of the Self) forging a theatrical pedagogy of biopolitics that incorporates in its dramaturgical and improvisational scope advanced technologies of judgment and decision about population problems (oppressions).

Keywords: Theatre of the Oppressed, Theatrical pedagogy, Augusto Boal, Michel Foucault.

A trajetória do diretor Augusto Boal pelos agitados grupos teatrais brasileiros dos anos 1950 e 1960 mostrou que não bastava chegar até o povo com a peça que o representava em cena. Algumas de suas experiências indicaram que o trabalho de conscientização que os grupos propunham não contemplava a necessidade do povo de contar a própria história. Pelo contrário, eram histórias do povo contadas por um dramaturgo inspirado e por um grupo de atores da classe média, ou seja, pessoas do teatro que nunca haviam pas- 
sado fome mas falavam da fome, reforma agrária, socialismo, opressão etc. O trecho a seguir representa o relato de Boal desta fase de sua trajetória no teatro:

Triste felicidade. O Arena, no Nordeste, havia encontrado o nosso povo; o CPC, no Rio, encontrara o seu. Embora dialogando com o povo, continuávamos donos do palco, o povo na plateia: intransitividade. Em Santo André, pessoas e personagens engalfinhavam-se em cena - isso aconteceu em um dia, um só: o verão precisava de mais andorinhas - águias, carcarás. [...] Continuava a divisão de classes, perdão, palco e plateia: um falava, outro escutava. A plateia cantava no coro mas não interferia no enredo. Agora, com a repressão, nem palco nem plateia: o povo tinha sido expulso dos teatros, sindicatos, associações, paróquias - povo proibido. Teatro outra vez assunto de classe média e intelectuais. Cada povo no seu canto, cada vaca no seu box. Dando leite, trabalhando. (BOAL, 2000, p. 230)

O sistema curinga desenvolvido nos musicais "Arena conta..., série escrita e dirigida por Augusto Boal e Gianfrancesco Guarnieri no Teatro de Arena de São Paulo, propunha o revezamento de atores na interpretação de personagens. $O$ desenvolvimento do curinga levou Boal a esquematizar uma forma de expandir esse revezamento dos atores ao público: criou assim o Teatro-Fórum. O desdobramento desse trabalho culminou no projeto chamado Teatro do Oprimido que se desenvolveu com experiências brasileiras e internacionais sendo atualmente praticado por diversos grupos de todo o mundo.

A partir do "teatro do oprimido" Boal deixou, na prática, de fazer teatro para fazer diretamente política. Mas não renunciou ao rótulo de teatro para suas especulações, o que não leva à outra conclusão, então, de ser o jogo viciado e autoritário do teatro do oprimido o Teatro da Opressão. (MOSTAÇO, 1983, p. 74)

O propósito do Teatro do Oprimido enunciado por Boal (2005a) é o de favorecer a compreensão de problemas pessoais e comunitários pelos participantes e promover a busca conjunta de alternativas para a resolução desses problemas. Para Oliveira e Silva (2005), por meio do Teatro do Oprimido o indivíduo pode "imaginar variantes do seu agir e racionalizar transformações pessoais que, a longo prazo, serão grupais". Sanctum (2006) indica que mes- 
mo tendo fim os projetos ou grupos populares aos quais os indivíduos faziam parte, "a semente plantada dentro das pessoas que têm a oportunidade de conhecer o Teatro do Oprimido vai ser semeada de alguma forma, durante muito tempo". Ainda a respeito da continuidade de influência das experiências com Teatro do Oprimido na vida das pessoas, pode-se citar uma famosa frase de Boal: "O Teatro do Oprimido começa quando termina".

O Teatro do Oprimido procura por meio da prática de jogos, exercícios e técnicas teatrais estimular a discussão e a problematização de questões do cotidiano para oferecer uma maior reflexão das relações de poder mediante a exploração de histórias entre opressores e oprimidos (TEIXEIRA, 2005). Em sua intervenção, os textos são construídos coletivamente a partir das histórias de vida dos atores e do público: cria-se uma dramaturgia que emerge de experiências e problemas típicos da coletividade, como a discriminação, o preconceito, o trabalho etc. Nas encenações teatrais são incentivadas a ridicularização do poder, a inversão da hierarquia, a violação do decoro e a ruptura com as normas impostas pelo dominador (CARVALHO; CARVALHO, 2004).

A chamada "Estética do Oprimido", a partir da qual a criação artística significa um caminho de descoberta expressiva e subjetiva do mundo, intenta um posicionamento em contraste com as instituições e com os valores dominantes que criam subjetividades padronizadas. Tendo como base histórica de desenvolvimento o Teatro do Oprimido, esta estética incorpora os instrumentos de outras artes no sentido de possibilitar a instauração de meios sensíveis de ação humana que não se restrinjam à razão ou à simbologia.

O Teatro do Oprimido - como Arte que é -, sem desvalorizar a Palavra, procura estimular nos seus participantes, através dos sentidos, o Conhecimento e o Pensamento Sensíveis em cada instante da Ação teatral, metáfora da vida, em cada Imagem e em cada Som. Vai além, e procura conhecer a própria Palavra como objeto sensível, pois entende que toda Sintaxe é Poesia - pode ser ruim, mas é poesia. (BOAL, 2006)

A Estética mencionada é do oprimido porque se propõe a possibilitar uma apropriação dos meios de produção artística por parte do homem que, nos tempos de hoje, encontra-se condicionado a dialogar com uma subje- 
tividade obscura corporificada em imagens, sons e palavras alheias à sua própria humanidade. Trata-se de empoderamento humano diante das imposições de uma arte ou cultura opressoras produzidas por terceiros, por diversos motivos, exceto o da descoberta da sensibilidade.

Considera-se que está no público a grande preocupação deste projeto. Enquanto as obras teatrais escritas para públicos da classe média são apresentadas em forma de espetáculo por atores profissionais, em teatros reconhecidos socialmente, os processos teatrais criados pelos atores não profissionais, muitos deles marginalizados socialmente, são realizados na e com a comunidade a qual pertencem. Não haveria diferença entre ator e público: a comunidade é protagonista da arte e da vida (BABBAGE, 2004). É a própria comunidade que constrói a obra, seja no processo de montagem seja nas apresentações. O papel do público no Teatro do Oprimido pode ser resumido pelo termo expect-atores, espectadores que estão na expectativa de serem atores (BOAL, 2005a).

Com o Teatro do Oprimido, a questão fundamental para Boal passou a ser: como tornar o espectador do povo o ator principal de uma montagem de teatro? É instigante como a nova proposta de recepção teatral, ou seja, de relação da cena com a audiência, visou operar pedagogicamente uma inversão de papéis ou de ponto de vista entre atores e espectadores. Se, para Boal, a cena anterior ao Teatro do Oprimido era intransitiva ("continuava a divisão de classes, perdão, palco e plateia: um falava, outro escutava" - BOAL, 2000, p. 230), agora os espectadores que participam da obra têm papel decisivo: criam sua própria estética, a própria forma de fazer teatro.

Uma das ideias centrais do Teatro do Oprimido, a de que todos são atores, inclusive os atores (BOAL, 2005b), refere-se à tese de Boal de que o teatro é inerente ao ser humano, o único que pode agir mas também se perceber agindo, sintetizando, assim, as funções do ator e do espectador de teatro. Considera-se que a linha argumentativa de que há uma pré-condição humana de fazer teatro foi elaborada no sentido de ampliar a difusão das práticas do Teatro do Oprimido sem que fosse contemplado um trabalho mais intenso com a pesquisa e experimentação teatral. De acordo com Mostaço (1983), Boal encobre o que seria uma vocação para atuar profissionalmente no teatro e ainda não leva em conta todo o preparo que é preciso ter para fazer teatro. Outra reflexão interessante é a de Nunes (2004, p. 70) que pondera a ques- 
tão da possibilidade de qualquer pessoa praticar teatro com outros sentidos: “qualquer pessoa pode? Há nesse 'pode' não uma questão de permissão ou capacidade, mas já de disposição e disponibilidade".

Não apenas a temática das peças, mas a própria composição do "elenco" teatral com atores do público indica como Boal possivelmente encarava a configuração da relação palco e plateia como um desajuste de poder. Constitui-se, assim, uma estética que visa lidar não apenas com a opressão nas relações humanas de modo geral, mas com a opressão que se dá no próprio teatro. $O$ foco de análise não está, então, nem no oprimido, nem no opressor, mas na própria estética de tratamento das opressões. Opressão é ação sobre ação e não ação sobre o outro. De acordo com Foucault (1995):

[O poder] é um conjunto de ações sobre ações possíveis: ele opera sobre o campo de possibilidades aonde se vêm inscrever o comportamento dos sujeitos atuantes: ele incita, ele induz, ele contorna, ele facilita ou torna mais difícil, ele alarga ou limita, ele torna mais ou menos provável; no limite ele constrange ou impede completamente; mas ele é sempre uma maneira de agir sobre um ou sobre sujeitos atuantes, enquanto eles agem ou são susceptíveis de agir. Uma ação sobre ações. (p. 243)

A partir da abordagem da genealogia de Foucault, desenvolve-se neste ensaio uma análise acerca da tentativa de Boal em abordar a tensão entre palco e plateia como uma relação desigual de poder. Antes que se constituísse a ideia de uma estética do oprimido, de apropriação dos meios de produção da cena pelo espectador, trata-se de considerar que houve no século xx $\mathrm{o}$ aprimoramento de uma tecnologia pedagógica no teatro a partir da qual se elaboraram sistemas de exercícios de si. Essa perspectiva, embora ainda centrada no ator e não no espectador, se desenvolveu tendo por base as experiências pedagógicas dos sistemas teatrais que objetivaram a produção da espontaneidade e da tomada de decisão pelos sujeitos em cena.

Conforme explicita Foucault (1995), não é o poder, mas o sujeito o tema geral de suas investigações. $O$ filósofo busca compreender a maneira como o ser humano se transforma em sujeito a partir de processos de sujeição e subjetivação. De acordo com Castro (2009, p. 408), "Foucault fala dos modos de subjetivação como modos de objetivação do sujeito, isto é, modos em que o sujeito aparece como objeto de uma determinada relação de conhecimento e de poder". 
A reflexão acerca dos mecanismos de constituição do sujeito, circunscritos nas práticas pedagógicas do teatro, tal qual elaborada por Icle (2007), trazem um olhar complementar à possível relação de poder estabelecida entre palco e plateia. Problematiza-se, assim, a discussão da participação na cena, questionando-se se não seriam os mecanismos de inclusão no processo produtivo da arte justamente os que promovem a sujeição. Investiga-se, dessa forma, a genealogia dos procedimentos teatrais do governo de si.

A pedagogia teatral se caracteriza por uma inovação que emerge no final do século xIx na Rússia a partir das experiências e sistematizações do diretor de teatro Constantin Stanislavski. Trata-se da transformação do foco do teatro de espetáculo profissional para a formação dos sujeitos. Stanislavski já sugeria uma metodologia que, para além da capacitação de atores para a cena, poderia prover o homem de instrumentos para melhorar sua própria vida (ICLE, 2007). Assim, os efeitos deste teatro pedagógico não estão ainda no campo da recepção, dos espectadores, mas no dos jogadores e praticantes que participam da composição da cena.

A reflexão de Pupo (1999) a respeito do caráter pedagógico do fazer teatral de grandes diretores de teatro também compreende a relevância, para eles, da formação dos participantes em termos da ética do sujeito:

Muitos dos diretores responsáveis pelas grandes transformações teatrais do último século, tais como Stanislavski, Grotowski ou Barba de certa forma foram também pedagogos. De modo radical eles sempre associaram a depuração de sua arte ao desenvolvimento pessoal daqueles que a praticam. Para eles a superação de si mesmo se coloca como uma meta inseparável da realização de um teatro que transcenda códigos já consagrados. Preceitos de caráter ético sempre acompanharam seu projeto de renovação teatral. (p. 32)

A tradição anterior a esses diretores se pautava no texto, cuja origem literária ou dramatúrgica prevalecia na criação e determinação da verdade cênica. O papel dos atores e outros funcionários do teatro era o de interpretar a obra (que já vinha pronta), seguir o roteiro e convencer o público acerca da genialidade dos autores clássicos. Já com a pedagogia teatral, a centralização do processo criativo está na figura do ator: o sujeito da cena, constituído 
da verdade de seu papel, canaliza o esforço de criação de uma obra que se inspira no texto, mas não é mais textocêntrica.

Foucault (1995) demonstra que na passagem do poder pastoral ao disciplinar o governo de si tem papel fundamental. Enquanto no poder pastoral havia quem cuidasse do rebanho, no disciplinar a ordem depende, sobretudo, da disciplina de si sobre si mesmo. É nessa passagem que se processa a instauração do teatro pedagógico. Antes havia um texto ou um dramaturgo centralizador que respondiam pela obra teatral, mas depois a responsabilidade da cena passou para os atores que cuidam uns dos outros, e cada um de si, para que haja sucesso na produção. Entretanto, a pedagogia do teatro também é uma autoorientação ética organizada na instrumentalização dos atores para o exercício de si com o objetivo de se humanizarem. Se antes o papel dos atores era o de reprodução, mímica e repetição, tornou-se, então, a improvisação e a imaginação interior. Trabalhar o personagem é um processo que antes requer um aprofundamento no trabalho de ator.

No âmbito da escrita teatral pode ter ocorrido também a passagem de um poder soberano para o poder disciplinar. Boal (2005a) observa as características principais da tragédia a partir da leitura da obra de Aristóteles Arte poética ${ }^{1}$. De acordo com a perspectiva de Boal sobre o sistema aristotélico, a catástrofe das tragédias era inevitável:

Não se permitem happy-endings, embora não seja necessária a destruição física do personagem portador da harmatia. Alguns morrem, enquanto outros veem morrer seus entes queridos. De qualquer forma se trata sempre de uma catástrofe em que não morrer é pior do que morrer (veja-se o caso de Édipo). (BOAL, 2005a, p.77)

Ao partir dessa conclusão de Boal sobre o desfecho dramatúrgico da tragédia, considera-se que o poder se exercia ali pela máxima do fazer morrer e deixar viver tal qual o poder soberano conceituado por Foucault. Desejavase a morte do herói, cujo erro (harmatia) devia ser purificado por meio de um processo catártico. Era preciso fazer morrer a anormalidade, a imoralidade e

1. O ensaio de Boal sobre Aristóteles é avaliado por Nunes (2004) tomando por base o referencial teórico de Roubine (2003) sobre o teatro aristotélico. Embora se trate de um debate da história do teatro em que há muitas discordâncias, a autora considera válidos os elementos e ideias utilizados por Boal para defender sua tese sobre a tragédia grega. 
o crime para deixar viver a harmonia e o coro, soberania dos cidadãos gregos. É possível depreender da análise de Boal que o poder da tragédia se impunha como terror repressivo sobre a morte.

Em tempos modernos, com o advento do drama (SZONDI, 2001) a partir de uma recriação da tragédia aristotélica pelo movimento do classicismo francês ${ }^{2}$, os sujeitos desenvolvem a ação dramática por meio das tecnologias do eu com o fim de manutenção da vida. Trata-se de uma perspectiva que se alinha à disciplina do sujeito em Foucault. Desenvolve-se a psicologia das relações e a novela dos conflitos e diálogos intersubjetivos, constituindo-se o teatro do drama burguês que faz viver o herói e deixa morrer os coadjuvantes, os figurantes e o coro do povo.

Icle (2007) trata da genealogia do cuidar de si a partir da consideração das técnicas de sistemas de interpretação (treinamento de ator), as quais emergiram com a pedagogia teatral de Stanislavski. A leitura de sua obra sugere os seguintes questionamentos: $O$ que tornou possível concebermos o teatro como um procedimento de expansão de nossas vidas? Como se deu a passagem de um teatro de espetáculo baseado na disciplina da conscientização para o teatro pedagógico do controle de nós mesmos?

O teatro realista russo foi marco importante na constituição da pedagogia teatral. Entretanto, os sistemas teatrais produzidos ao longo do século $x \mathrm{x}$ provocaram outras relações do sujeito consigo mesmo, a partir da intensificação dos processos improvisacionais de criação artística e de recepção. No Teatro do Oprimido, a pedagogia teatral se exerce pela empatia das histórias de si cuja motivação é a da livre transformação da ação dramática por parte do espectador. É justamente na modalidade do Teatro-Fórum que culminará em sua experiência: o público participa da cena e se torna sujeito da ação teatral. Entretanto, nas técnicas do Arco-íris do desejo (BOAL, 1995), em que se promove uma terapia de si no coletivo, caracteriza-se declaradamente $\mathrm{O}$ exercício das tecnologias do sujeito aplicadas ao autoconhecimento e transformação das opressões individuais e sociais.

É interessante que Boal, à sua maneira e se propondo transformador, está, talvez sem querer reconhecer, um tanto engatado nesse eixo: des-

2. Conforme a leitura de Roubine (2003). 
de sua concepção sobre o ator até seu mergulho posterior em pesquisa de técnicas de terapia - ainda que ele diga que a proposta aí é uma coletivização de todos os problemas mostrados e a busca conjunta de soluções -, o indivíduo, o sujeito psicológico está, para ele, subentendido e naturalizado. Por isso, produz um "teatro de transgressão"; que age mais no nível molar, tentando mudar situações estabelecidas, porém, no nível molecular, muitas vezes convoca o mesmo tipo de esquema/esquadrinhamento perceptivo daquilo a que diz se opor. (NUNES, 2004, p. 113)

Se a tragédia é o campo fértil do poder soberano sobre o personagem, o drama moderno seria o modelo de exercício do poder disciplinar sobre o ator a partir da emergência do cuidado de si dos novos sistemas de interpretação. Com o Teatro do Oprimido, a pedagogia teatral ganhou um estágio de governo e se estendeu ao espectador por meio das políticas públicas. A estatização dos processos teatrais exige não mais o rigor do trabalho do ator ou a purificação repressiva do herói trágico. O teatro do fazer viver requer a gestão das demandas populacionais e sua incorporação ao aparato legal. Assim, a obra de Augusto Boal foi um dos marcos que instauraram o biopoder no teatro a partir da incorporação pela pedagogia do teatro das tecnologias de julgamento e decisão na dramaturgia do Teatro-Fórum e dos processos constitucionais e jurídicos do Teatro Legislativo.

Entretanto, essa passagem não faz que o poder disciplinar do drama seja extinto no Teatro do Oprimido. De acordo com Foucault (2002, p. 287), o biopoder não irá apagar o poder disciplinar, que nesta leitura é aproximada ao drama no teatro, mas "penetrá-lo, perpassá-lo, modificá-lo". Dessa maneira, Castro (2009) aborda as transições do poder:

[...] não se trata de pensar a história do poder moderno como a substituição de uma sociedade de soberania por uma sociedade disciplinar e, depois dessa por uma sociedade de governo das populações. Antes, atualmente encontramos um triângulo soberania-disciplina-gestão governamental cujo objetivo fundamental é a população, e seus mecanismos essenciais são os dispositivos de segurança. (p. 114)

É assim que no Teatro do Oprimido o objetivo fundamental se configuraria em termos da biopolítica no sentido de se instaurar uma via participativa de governo da população, mas preservando os dispositivos de 
segurança do drama cujo rigor ainda está pautado nas práticas disciplinares do cuidado de si: vigiar e punir. Assim, o que aparenta uma inconsistência estética em algumas passagens recentes da obra de Augusto Boal, cujos enunciados temáticos de opressão buscam a ressonância do discurso coletivo e o enunciado formal tende a se caracterizar com padrões disciplinares do drama moderno, revelaria uma contradição do poder na contemporaneidade.

\section{Referências bibliográficas}

BABBAGE, F. Augusto Boal. Nova York: Routledge, 2004.

BOAL, A. The Rainbow of Desire: the Boal method of theatre and therapy. Nova York: Routledge, 1995.

Hamlet e o filho do padeiro: memórias imaginadas. Rio de Janeiro: Record, 2000.

Teatro do Oprimido e outras poéticas políticas. 7. ed. Rio de Janeiro: Civilização Brasileira, 2005a.

Jogos para atores e não atores. 8. ed. Rio de Janeiro: Civilização Brasileira, 2005b.

Quando nasce um bebê: o pensamento sensível e o pensamento simbólico no Teatro do Oprimido. Sala Preta, São Paulo, n. 6, 2006.

CARVALHO, J. L. F. S.; CARVALHO, F. A. A. Atores e papéis no ensino da administração: estudo de caso em uma empresa júnior. In: XXVIII ENCONTRO ANUAL DA ANPAD, 28., 2004, Curitiba. Anais... Curitiba: Associação Nacional dos Cursos de Pós-Graduação em Administração, 2004.

CASTRO, E. Vocabulário de Foucault: um percurso pelos seus temas, conceitos e autores. Belo Horizonte: Autêntica, 2009.

FOUCAULT, M. O sujeito e o poder. In: RABINOW, P.; DREYFUS, H. Michel Foucault: uma trajetória filosófica para além do estruturalismo e da hermenêutica. São Paulo: Forense Universitária, 1995.

FOUCAULT, M. Em defesa da sociedade. São Paulo: Martins Fontes, 2002.

ICLE, G. Pedagogia teatral como cuidado de si: problematizações na companhia de Foucault e Stanislavski. In: 30ª REUNIÃO ANUAL DA ASSOCIAÇÃO NACIONAL DE PÓS-GRADUAÇÃO E PESQUISA EM EDUCAÇÃO, 2007, Caxambu. Anais... Rio de Janeiro: ANPED, 2007. v. 1. p. 35.

LEAL, D. Narrativas da participação: estudo foucaultiano sobre a poética do teatro do oprimido nas plenárias de orçamento participativo em Santo André. 2010. Dissertação (Mestrado em Controladoria e Contabilidade) - Universidade de São Paulo, São Paulo, 2010. 
MOSTAÇO, E. Opressão: o mito oculto do Teatro do Oprimido. In: MOSTAÇO, E. O Espetáculo Autoritário: pontos, riscos, fragmentos críticos. São Paulo: Proposta, 1983.

NUNES, S. B. Boal e Bene: contaminações para um teatro menor. 2004. Tese (Doutorado em Psicologia Clínica) - Pontifícia Universidade Católica de São Paulo, São Paulo, 2004.

OLIVEIRA, D. F.; SILVA, L. C. S. Economia Solidária e Teatro do Oprimido: um diálogo possível. In: III ENCONTRO INTERNACIONAL DE ECONOMIA SOLIDÁRIA, 2005, São Paulo. Anais... São Paulo: Núcleo de Economia Solidária da USP, 2005.

PUPO, M. L. S. B. Além das dicotomias. In: SEMINÁRIO NACIONAL DE ARTE E EDUCAÇÃO, 1999, Montenegro. Anais... Montenegro: Fundarte, 1999.

ROUBINE, J-J. Introdução às grandes teorias do teatro. Rio de Janeiro: Jorge Zahar, 2003.

SANCTUM, F. O Teatro do Oprimido na diversidade sexual. Revista Recrearte, Santiago de Compostela, v. 5, 2006.

SZONDI, P. Teoria do drama moderno. São Paulo: Cosac Naify, 2001.

TEIXEIRA, T. M. B. Dimensões sócioeducativas do Teatro do Oprimido de Augusto Boal. Revista Recrearte, Santiago de Compostela, v. 4, 2005.

Recebido em 12/03/2015

Aprovado em 23/05/2015

Publicado em 30/06/2015 